C.I.F. T. XIV (1988), págs. 99-106

\title{
ESPEJOS Y REFLEJOS EN LA OBRA DE MARGUERITE YOURCENAR
}

\author{
M. José Vázquez de Parga y Chueca* \\ I.B. «Canarias Cabrera Pinto» de La Laguna
}

\begin{abstract}
RESUMEN
Marguerite Yourcenar emplea con frecuencia las imágenes de espejo. En su sentido más profundo, los espejos de Yourcenar reflejan el universo. Podríamos agruparlas en imágenes de espejo del universo de Demócrito o espejo alquímico, en donde el hombre es reflejo del universo, e imágenes de espejos reflejando el tiempo y la historia. Unos espejos reflejan el tiempo futuro mientras otros reflejan el presente y otros el pasado. Algunos abarcan toda la gama temporal. Otras veces la imagen de espejo prescinde del espejo material para mostrar el reflejo del universo en una persona real o un retrato. Los espejos de Yourcenar son empañados, rotos, o de agua oscura, que más que reflejar al que se mira, reflejan el universo, la historia, el tiempo y la vida.
\end{abstract}

\begin{abstract}
Yourcenar's employ of frequent mirror images is, in its inner meaning, to reflect the universe. We can group them in images corresponding to the Democrite's universe or alchemic mirror -where man is reflex of the universe-, and images of mirrors reflecting time and history. Some of them reflect the future time while others reflect present or past. There are some mirrors that comprise the whole temporal range. Sometimes the image of mirror prescinds of the material mirror in order to reflect the universe over a real person or a portrait. Yourcenar mirrors are tarnished, dimmed, broken or made of dark water and reflect the universe rather than the one who is looking at them.
\end{abstract}

Si bien la imagen del espejo es frecuente en literatura, no deja por eso de presentar un gran interés. Con frecuencia la utiliza Marguerite Yourcenar. Acude a su pluma fácilmente para mostrar a través de una misma imagen conceptos diferentes, pero desem-

* Dra. en Filosofía y Letras (Filología Moderna). Instituto de Bachillerato «Canarias Cabrera Pinto», La Laguna (Tenerife). Recibido el 25-3-88. 
bocando todos en el mismo: el hombre como reflejo del cosmos, del universo, de sí mismo. Es un principio filosófico, alquímico y religioso que abarca todo su pensamiento.

El hombre reflejo del cosmos y formando parte de él es una de las teorías presocráticas, pero era ya premisa de las sabidurías orientales y, antes de ellas, de los pueblos protohistóricos; el taoísmo y el budismo, el zen y el tantrismo, parten de los mismos principios.

La alquimia, cuyos orígenes desconocemos y que se remontan para algunos autores a más de treinta milenios antes de J.C. poseía estos conceptos básicos probablemente antes de que se desarrollaran las religiones orientales y, por supuesto, mucho antes del auge de los filósofos presocráticos. Mircea Eliade expone varias fechas para los primeros textos alquímicos escritos, puesto que los especialistas no están de acuerdo en ello, y señala que, para Dubs, el fundador de la alquimia china sería Tsu Yen, un contemporáneo de Mencius, en el siglo IV ${ }^{1}$. Pero para Mircea Eliade los elementos de la alquimia, principios, mitos y técnicas, «pertenecían a la herencia cultural de la protohistoria y sería un error creer que la fecha de los primeros documentos que la atestiguan nos indican igualmente su edad $»^{2}$. Pedro Guirao cita la tesis de Manetón, trasmitida por Eusebio de Cesarea, que sitúa al autor del Corpus Hermeticum, a Hermes-Thot, entre el 16.644 y 30.544 a. de J.C., y lo considera escriba y señor de la magia, funcionario de la época anterior al linaje de los reyes, o sea perteneciente a la dinastia de los semidioses ${ }^{3}$. Fulcanelli, en la conversación que se hizo famosa y que mantuvo en el laboratorio de André Helbronner, con Jacques Bergier, le atribuye a la alquimia por lo menos cuatro mil años de antigüedad y la considera como procedente de las antiguas civilizaciones destruidas ${ }^{4}$.

Que los principios de la alquimia son los mismos en que se basan las religiones orientales, es a su vez afirmado por Mircea Eliade, para quien hay una «simbiosis entre el yoga tántrico y la alquimia» ${ }^{5}$. En algunos textos alquímicos incluso se enseña al discípulo a venerar a Siva «pues la alquimia ha sido revelada por el propio Siva» ${ }^{6}$.

Los textos taoístas mencionan técnicas y elementos de la alquimia comunes con el budismo zen y el tantrismo, Ko-Ch'ang-Ken lo reconoce: «Si se nos objeta que este método es exactamente el de los budistas zen, respondemos que bajo el Cielo no existen dos Caminos y que los Sabios son siempre del mismo parecer» ${ }^{7}$.

Marguerite Yourcenar conoce y traduce a los presocráticos, y emplea sus teorías en la concepción de sus obras; las religiones orientales han sido su alimento espiritual y no puede prescindir de ellas; pero sobre todo, Marguerite Yourcenar es alquimista.

Bajo el prisma de la alquimia analizaremos algunas de las imágenes de espejo que encontramos a lo largo de la lectura de las obras de M. Yourcenar. Otras son temporales, y es en la medida del tiempo como reflejan la historia individual y de la humanidad.

En alquimia, la imagen del espejo se utiliza en múltiples simbolismos; se habla de materia prima como espejo del espíritu universal. Espejo es también el fondo del alma, que brilla como la plata y refleja la luz del espíritu.

Pero el simbolismo que mejor define a la alquimia es el del hombre como espejo del universo. El hombre es un microcosmos reflejando al macrocosmos y hecho de la misma materia que él. Puesto que todos estamos hechos de la misma materia que los

1. ELIADE, Mircea, Herreros y Alquimistas, pág. 101.

2. Ibid, pág. 102 .

3. GUIRAO, Pedro, La Alquimia Desvelada, pág. 14.

4. Ibid, pág. 83 .

5. ELIADE, Mircea, Obra cit., pág. 113.

6. Ibid, pág. 118.

7. Ibid, pág. 111, citando a Waley. 
astros, como dice Adriano, «et puisque l'homme, parcelle de l'univers, est régi par les mêmes lois qui président au ciel» (M.H. p. 162), cumplimos la ley de la Tabla Esmeraldina que afirma que «lo de arriba es igual a lo de abajo y lo de abajo es igual a lo de arriba».

Zenon se ve reflejado en un espejo florentino de veinte caras y en él contempla a veinte filósofos iguales cuyos ojos brillan a su vez como espejos. Espejos del alma. Esa figura repetida veinte veces le recuerda la hipótesis del griego Demócrito: «une série infinie d'univers identiques où vivent et meurent une série de philosophes prisonniers» (O.N. p. 187). En el espejo de Zenon se refleja el universo; no sólo el mundo, sino todos los mundos. Zenon se refleja en el espejo precisamente cuando acaba de tomar una decisión definitiva: huir a Brujas y vivir allí escondido bajo un falso nombre para dedicarse a lo que le parece el único camino posible: la purificación de su espíritu. Es el comienzo del proceso espiritual que le veremos elaborar en el capítulo «L'abîme». No es una huida de sí mismo sino del mundo que le persigue, para centrarse más en sí mismo como microcosmos, para intentar conocerse y conocer así el universo.

La alusión a Demócrito en este punto de la novela es interesante. El filósofo griego es el representante de la teoría atomista mecanicista del universo, que concuerda con las premisas alquímicas. El universo todo está formado por átomos que son todos ellos de la misma materia, difieren unos de otros cuantitativamente pero no cualitativamente. Estos átomos están sin cesar en continuo movimiento, y de ese movimiento surgen los cuerpos, los mundos infinitos, iguales y paralelos los unos, distintos los otros. Esta teoría de la materia, semejante a la alquímica, la encontramos citada de nuevo al final de la novela en el momento del proceso, cuando Zenon tiene que defenderse ante los tribunales y tiene que responder, puesto que «la question de l'infinité des mondes» preocupaba más particularmente a los teólogos llamados en calidad de auditores (O.N. p. 389). Su respuesta es acercar sus teorías a las de San Buenaventura, «qui implique une certaine corporalité des âmes» (O.N. p. 390). Esa unidad de la materia expresada en forma temporal, es la imagen de Zenon confundiendo en su mente el tiempo, el espacio y su propio ser: «Zenon lui-même se dissipait comme une cendre au vent» (O.N. p. 237). Es la teoría de Demócrito la que evoca Adriano al sostener que «dans un monde où tout n'est que tourbillon de forces, danse d'atomes, où tout est à la fois en haut et en bas, à la périphérie et au centre, je concevais mal l'existence d'un globe immobile, d'un point fixe qui ne serait pas en même temps mouvant» (M.H. p. 162). Son de nuevo los átomos de la teoría atomista y mecanicista, el movimiento continuo, usado esta vez por Adriano para compararlo con los ritos de Eleusis.

La teoría atomista sigue en plena actualidad entre los alquimistas. E. Canseliet, en el prólogo a la tercera edición del libro de Fulcanelli, en la misma forma velada que es propia de todo alquimista, habla de cómo el atomismo científico moderno no ha llegado aún a nada parecido a lo que el atomismo puede hacer en la alquimia; de los sabios actuales dice: «Para entonces la atomística parece ilustrar muy bien la inmensa cadena de montañas que, luego de no menos ilimitados dolores, dé a luz una chispa casi microscópica» ${ }^{8}$.

El valor de la alquimia es que es espejo de verdades espirituales. La contemplación de la naturaleza permite reproducir en un caso visible los grandes procesos de la naturaleza. Esta verdad se encuentra en las palabras de Muhyi-d-Dîn Ibn 'Arabî: «El mundo de la naturaleza consiste en múltiples formas que se reflejan en un único espejo; no, más bien es una forma única que se refleja en múltiples espejos»?. 
Estamos de nuevo ante la imagen de Zenon contemplándose en veinte espejos. ¿Está realmente pensando en Demócrito al contemplarse? ¿O es la gran verdad alquímica la que se le presenta de forma global en el espejo florentino? Es esta verdad alquímica la que empuja al médico filósofo y alquimista a tomar el camino de Brujas, es la única que tiene sentido para él y a la que va a dedicar el resto de su vida, comenzando los cambios de la trasmutación espiritual que le harán superar la Obra Negra.

En plena fase de disolución, cuando Zenon busca el sentido de los conceptos, cuando más ha intentado conocerse a sí mismo, y cuando menos sabe «d'un homme, qui était soi-même» ( $O . N$. p. 244), es cuando aparece de nuevo la imagen del espejo. Esta vez el espejo es una lupa, y la imagen en él reflejada es la del ojo de Zenon, considerablemente ampliada por la lente, de tal forma que al verla en un principio, al despertar de su sueño campestre, el filósofo no puede reconocer el órgano, que confunde con un animal, insecto o molusco, que se movía constantemente en la sombra (O.N. p. 242). Pronto se dio cuenta de que lo que veía a través del espejo formado por la lupa con la arena y la hierba que tenía detrás, no era sino el órgano «dont il dépendait pour voir l'univers»; el conocimiento de sí mismo y del universo se enriqueció notablemente y «cet oeil humain devenait un symbole».

Otro espejo que refleja el universo es el canal de Amsterdam en el cuento «La tristesse de Cornélius Berg», en donde «ce terne miroir plombé», que no reflejaba más que lo que estaba a su alrededor, reflejaba en realidad para Berg toda la bondad y toda la maldad del universo (N.O. p. 142). El agua de los canales de Amsterdam sería «agua dormida» como la de los canales de Brujas para Bachelard ${ }^{10}$; agua negra y profunda que no refleja claramente la imagen que tiene delante, sino que se presta a ver en ella lo que la imaginación del que se mira proyecta. Por eso Cornélius Berg «y contemplait vaguement toute sa vie», con todos los países que había visitado y todas las personas que de algún modo habían compartido sus vivencias, con todo el dolor que el mundo había dejado en él.

El sueño del Durero, representando un enorme cataclismo de la naturaleza, le produce a Marguerite Yourcenar la sensación de que es «tel qu'il aurait pu se réfracter dans un bloc de cristal en l'absence d'un oeil d'homme» (L.T. p. 72). Es una imagen que para M. Yourcenar no posee subjetivismo, sin embargo ese realismo de la imagen no podría darse sin una fuerte imaginación de Durero; el grabado de Durero es en realidad como ese ojo que refleja la naturaleza.

En el espejo de Sophie, en Le Coup de Grâce, hay un narcisismo negativo; no dice, «me amo tal cual soy», sino todo lo contrario. Mira en el espejo el reflejo de una imagen encantadora, joven, cándida, que no complace en absoluto a Sophie, que quisiera en ese momento ser de otra manera para complacer al hombre que ama sin ser correspondida. Es una contemplación neurotizante, una no aceptación de la realidad tal como es ante el espejo, «elle eut horreur de toutes ces choses qui la trahissaient» (C.G. p. 173). La imagen que ve en el espejo, aunque descrita por Eric, que no es el reflejado, participa de la visión de la naturaleza, por lo tanto el espejo se convierte en algo vivo: «la glace lui renvoya des yeux d'enfant et d'ange, un large visage un peu informe qui était la terre même au printemps, un pays, des campagnes douces traversées de ruisseaux de larmes; des joues couleur de soleil et de neige...». Para Bachelard «los espejos de cristal, en la viva luz de la habitación, dan una imagen demasiado estable. Llegarán a ser vivos y naturales cuando se les pueda comparar con un agua viviente y natural, cuando la imaginación renaturalizada pueda recibir la participación de los espectáculos de la fuente y del río» ${ }^{11}$. 
Podemos catalogar otro número de imágenes de espejos bajo el título de imágenes del tiempo y de la historia. "Tels sont les jeux de miroirs du temps» (S.P. p. 210), exclama M. Yourcenar después de hacerse contemporánea de su tío Octave en un 23 de octubre de 1875 .

Los espejos de Marguerite Yourcenar son en su mayoría históricos: reflejan el pasado. Encontramos algunos reflejando el futuro, que, como afirma Bachelard, es porque el narcisismo que lleva aparejada toda contemplación en el espejo, «está ligada casi fatalmente a una esperanza»; meditando sobre su belleza Narciso medita sobre su porvenir $^{12}$. Eso es exactamente lo que le ocurre a Lazare. El muchacho que huye de la casa de Mevrouw Loubah, llena de espejos de Venecia en donde las sobrinas y los señores que las visitaban se contemplaban desnudos, se contempla a su vez en un espejo roto por el que ve desfilar, bajo forma de personajes teatrales, toda su vida futura, todos los hombres, mujeres y niños que podría encarnar hasta su vejez, y aun entonces, los pequeños trabajos que quedarían para él, «le petit Lazare était sans limites, et il avait beau sourire amicalement au reflet de lui-même que lui renvoyait un bout de miroir fiché entre deux poutres, il était sans forme: il avait mille formes» (B.M. p. 212).

Espejo de futuro es también el de Aquiles en Feux, que refleja al alba «tous les futurs aspects d'Achille, comme si ce mince morceau de glace avait emprisonné l'avenir» (F. p. 53).

Espejos históricos en donde se entremezclan simultáneamente los tres planos temporales de presente, pasado y futuro, son los espejos del laberinto de Teseo: «Est-ce contre ces murs de carton-pâte, contre ces parois plaquées de miroirs déformants que Thésée s'est battu?» (Q.M. p. 215). Espejos que observan la lucha del héroe consigo mismo, con lo que fue y con lo que será.

Alexis se contempla en el espejo y no se ve en él; no le dejan lugar sus antepasados que «continuaient à emplir de leurs images les miroirs de notre maison» ( $A$. p. 26). Esos antepasados cuyo recuerdo en la casa era tan poderoso que borraba casi la imagen de los que ahora vivian en ella, no le permiten a Alexis contemplar su propia imagen; el presente se ve suplantado por un pasado familiar abrumador, que no le permite a Narciso contemplarse a sí mismo.

Por otra parte, ese narcisismo imposible se asemeja a un texto hermético que habla de un espejo misterioso, colocado en un templo bajo siete puertas y shecho de manera que ningún hombre pudiera verse en él materialmente, pues tan pronto se colocaba ante el espejo, se olvidaba de su imagen». Alexis ante el espejo se olvida también de su propia imagen, no podía verla porque estaban solamente los antepasados. Pero cuando Alexis consigue, al marcharse de Woroïno, ver su imagen, se encuentra con que «mon âme, quand je la connus mieux, me dégoûta comme mon corps» $(A$. p. 76); que se aproxima a lo que nos cuenta el relato del espejo de las siete puertas, que «cuando el alma se mira en él, descubre la vergüenza que ella encierra y la arroja de sí». El relato del espejo encerrado en el templo se identifica con el filósofo que dice: «conócete a ti mismo», y «cuando un hombre se mira y se ve en él... al unirse con el Espíritu Santo se convierte en hombre completo» ${ }^{13}$.

Los antepasados no le dejan a Alexis la posibilidad de la contemplación narcisista, puesto que las efigies de ellos se superponen a la suya y la anulan. Es una de las razones que contribuyen a que Alexis se proclame a sí mismo con todos sus defectos, su homosexualidad es sólo suya, no de los antepasados y él necesita ser Alexis, no «la fin d'un lignage» (A. p. 25) que reinó en la casa y en el pueblo. El abuso que, en la mente 
de Alexis, cometen de él aquellos que le precedieron, es lo que empuja a Alexis a diferenciarse de ellos, a individualizarse aunque tenga que ser a costa de aceptarse tal como es. Entonces puede ya contemplarse en el espejo y verse. Narciso dice: «me amo tal cual soy» ${ }^{14}$.

Michel-Charles se contempla en el espejo y ve su propia imagen: es narcisista. Pero en su rostro observa otros rostros, los de los antepasados de los retratos de familia y que ahora aparecen y desaparecen sucesivamente tomando el lugar que le pertenece a él: «ce jeune homme a un de ces visages qui semblent appartenir, moins à l'individu... qu'à la race» (A.N. p. 102). Esta aparición de antepasados no anula su personalidad, como le ocurría a Alexis; el espíritu de Michel-Charles es otro. Admite a los antepasados, se siente su continuador y si se aparecen en el fondo del espejo no es para aniquilarlo a él sino para explicarlo, para prolongarlo en el tiempo. El espejo de Michel-Charles es un espejo histórico, es un espejo en el que se refleja la historia.

Espejo histórico también es el de Gemara, la mansión familiar de los di Credo, que, acostumbrado a reflejar a las personas de la familia desde hacía diez siglos, después de los sucesivos infortunios de sus componentes, de haber pasado de la «prehistoria» al momento actual, de haber tenido que integrarse en un mundo que no sabe nada de su Gemara, el espejo «ne les reconnaîtrait pas» (D.R. p. 75).

Esta misma imagen de la persona reflejando a los antepasados se da con semejante sentido en otros personajes, en que, sin necesidad de contemplarse o de contemplar en el espejo, son ellos mismos reflejo de los antepasados, reflejo de la Historia, que llevan como expuesta en su persona. Don Ruggero era «l'aboutissement d'une race», lo mismo que Alexis, y no sólo es ese final en que una raza ha terminado, sino que representa, en las distintas etapas de su vida, a personas de diferente época y lugar, completando en sí mismo una historia universal; se había parecido en una época a un efebo de los poemas de Píndaro, a la figura de un Cristo en un mosaico de Martorana, a un brujo musulmán en la Sicilia de la Edad Media. Don Ruggero era «un miroir fêlé où se reflétaient vaguement les revenants de la race» $\left(D . R\right.$. p. 56 ${ }^{15}$. Lo mismo nos muestra Conrad al morir: una serie de personajes de otras épocas que le antecedieron en ese trance a todos común, y ante el que se enfrentaron con una actitud semejante: «En quelques heures je le vis changer d'âge et presque changer de siècle: il ressembla successivement à un officier blessé des campagnes de Charles XII, à un chevalier du Moyen Age étendu sur une tombe, enfin à n'importe quel mourant sans caractéristique de caste ou d'époque, à un jeune paysan, à un batelier de ces provinces du Nord dont sa famille était sortie» (C.G. p. 232). Don Ruggero y Conrad son espejos vivos del pasado.

Espejos del pasado son a su vez los cuadros y fotografías que M. Yourcenar contempla y utiliza para reproducir las personas de unos antepasados que no conoció, de una familia que representa a una sociedad y a una historia. Detrás del retrato de Fernande aparecen las mujeres celtas que acompañaban a sus hombres a Macedonia o a Roma, y aún va más atrás, a las mujeres «des peuplades des fonds de cabane». Y todo simplemente porque Fernande tiene los párpados achinados como muchas mujeres de su país y como puede observarse en las que están retratadas en los cuadros de los pintores flamencos. A Marguerite Yourcenar le ocurre como a Alexis o a Michel-Charles; ellos veían a los antepasados en el espejo; M. Yourcenar los ve en los retratos. Es la imaginación la que proyecta esos antepasados tras la imagen real; de esa forma Marguerite Yourcenar se integra en la historia.

15. Denier du Rêve tiene profusión de imágenes de espejo, que han sido estudiadas por Farrell con un sentido exclusivamente narcisista. 
Todos estos personajes llevan en ellos mismos el pasado, son reflejo del pasado y de la historia. Nathanaël busca en Willem el reflejo de sí mismo; no de la historia ni del pasado, sino del presente que vive casi sin vivirlo. Necesita ver el rostro de Willem para recordar que él tiene uno también, «pour s'assurer qu'il en avait un lui-même», se mira en Willem como se miraría en el espejo (H.O. p. 165). Clément Roux se mira en Massimo y al ver su juventud y su vigor, su extrema belleza que «étant inattendue, surprenait comme l'eût fait une difformité» (D.R. p. 172), recobra por un tiempo la vida. Massimo se mira en Clément Roux y su vejez le anima a seguir viviendo, ese viejo que se recobra de una crisis de corazón «ne sait pas qu'il est pour moi une terre ferme» $(D . R$. p. 173). Son uno y otro reflejo de la vida, reflejo del presente.

Rosalia di Credo se ve en un «bout de glace brisée» que tenía sobre la cama y no se reconoce, considera su imagen como la de una extranjera puesto que no le devuelve la imagen interior, la decisión de morir. Es un espejo del presente irreconocible (D.R. p. 76).

Reflejo del presente y de la actualidad permanente alquímica sería de nuevo el espejo florentino de Zenon, con su pluralidad de mundos.

Los espejos de Marguerite Yourcenar en su mayoria son espejos empañados, espejos rotos, espejos en los que rara vez brilla la luz del sol o la claridad del día; espejos de agua del canal oscura y profunda. Para Bachelard las imágenes de los cristales tienen una solidez y una constancia que no tienen las imágenes reflejadas en el agua. Los de Marguerite Yourcenar están empañados o quebrados para evitar esa solidez; así las imágenes en ellos reflejadas se prestan a la ensoñación como si fueran un reflejo del agua. A su vez el agua es agua oscura, que no deja ver claramente la imagen que cae sobre ella sino la imagen que desea ver el que se contempla.

\section{BIBLIOGRAFIA}

Obras de Marguerite Yourcenar y abreviaturas:

L'Oeuvre au Noir, Gallimard, 1968, O.N.

Denier du Rêve, Gallimard, 1971, D.R.

Le Coup de Grâce, Gallimard, 1939, C.G.

Alexis, Gallimard, 1971, A.

Mémoiries d'Hadrien, Marguerite Yourcenar et Editions Gallimard, 1974, M.H.

Un homme obscur, Gallimard, 1985, H.O.

Une belle matinée, Gallimard, 1985, B.M.

Archives du Nord, Gallimard, 1977, A.N.

Souvenirs Pieux, Gallimard, 1974, S.P.

Nouvelles Orientales, Gallimard, 1963, N.O.

Qui n'a pas son Minotaure? Théâtre II, Gallimard, 1971, Q.M.

Feux, Marguerite Yourcenar et Editions Gallimard, 1974, F.

Le Temps, ce grand sculpteur, Gallimard, 1983, L.T. 


\section{Otros autores consultados:}

Bachelard, G., El agua y los Sueños, Fondo de Cultura Económica, México, 1978.

BuckHardT, Titus, Alquimia, Plaza y Janés, Barcelona, 1976.

Eliade, Mircea, Herreros y Alquimistas, Taurus, Alianza Editorial, Madrid, 1974.

FARrell, C.F., Jr. and FARRELl, E.R., Marguerite Yourcenar in counterpoint, University Press of América, 1983.

Fulcanelli, Las Moradas Filosofales, Plaza y Janés, Barcelona, 1972.

Fulcanelli, El Misterio de las Catedrales, Plaza y Janés, 1968.

Guirao, Pedro, La Alquimia desvelada, Teorema, Barcelona, 1979. 